\title{
NOTAS SOBRE O IX SIMPÓSIO BRASILEIRO DE CLIMATOLOGIA GEOGRÁFICA - 2010
}

\author{
Edson Soares Fialho*
}

Entre os dias 26 e 30 de setembro de 2010 ocorreu na cidade de Fortaleza- Ceará, o IX Simpósio Brasileiro de Climatologia Geográfica (SBCG), com a temática: Climatologia e Gestão do Território. A realização do evento foi uma promoção da Universidade Federal do Ceará (UFC) e da Associação Brasileira de Climatologia (ABClima), e a organização geral do evento coube às professoras: Maria Elisa Zanella e Marta Celina Linhares Sales, ambas da UFC. O evento foi estruturado em 6 eixos, nos quais se basearam a produção técnico-científica do simpósio: a) Climatologia: aportes teóricos, metodológicos e técnicos ( 52 trabalhos); b) Clima e ensino: abordagens e perspectivas (26 trabalhos); c) Impactos, riscos e vulnerabilidades socioambientais associadas ao clima (76 trabalhos); d) Climatologia urbana (112 trabalhos); e) Climatologia Agrícola (27 trabalhos); f) Outros (37 trabalhos), totalizando 330 contribuições.

Os participantes também tiveram a possibilidade de optar entre 7 minicursos ofertados: 1. Os sistemas atmosféricos e sua dinâmica no Brasil (Profa.. Denise Maria Sette-UFMT); 2. Estatística aplicada à Climatologia (Profa ${ }^{\text {. }}$ Teresinha de Maria Bezerra S. Xavier-Membro Titular e Diretora Científica da ACECI-Academia Cearense de Ciências); 3. Climatologia e Ensino: abordagens e técnicas (Profa ${ }^{a}$ Isorlanda Caracristi - UVA); 4. Desastres Naturais associados ao clima (Andrea Koga Vicente - Doutoranda - UNICAMP); 5. Climatologia Aeronáutica (Prof. Edson Cabral - PUC/SP); 6. Análise rítmica em Climatologia: aspectos conceituais e aplicações (Prof. João Afonso Zavattini - UNESP/RC); 7. Climatologia e Recursos Hídricos (Prof. Washington Assunção - UFU), além de 3 trabalhos de campo: Sertão de Quixadá (Coordenação Profa. Dra. Vanda de Claudino Sales/UFC); Serra de Baturité (Coordenação do doutorando Frederico Holanda/SEMACE) e o litoral do Morro Branco e de Canoa Quebrada (Prof. Dr. Edson Vicente da Silva/UFC e Profa. Dra. Adryane Gorayeb/UFC) que foram realizados no último dia do evento.

Ao longo da semana os temas foram distribuídos em 4 mesas redondas e 2 conferências. No primeiro dia fomos agraciados com a belíssima e desafiante conferência de abertura proferida pela Professora Ana Monteiro da Universidade do Porto, que versou sobre o clima e a gestão do território, destacando a cidade como espaço de (des)encontros entre a evolução do conhecimento e a qualidade de vida dos seres humanos.

No segundo dia, a primeira mesa apresentada tinha como título: A dimensão climática dos geo-ecossistemas brasileiros: aportes e desafios científico-técnicos e à gestão, que foi coordenada por Marta Celina Linhares (UFC) e como palestrantes os professores Emerson Galvani (USP), Charlei Aparecido da Silva (UFGD) e Francisco Evandro Aguiar (UFAM). Logo após o encerramento da mesa redonda, deu-se início de acordo com a programação, a homenagem pela comissão organizadora do IX SBCG e da ABCLIMA à Profa. Dra. Ana Maria de Paiva Macedo Brandão (UFRJ), a primeira presidente da ABCLIMA, 
conduzida de maneira emocionada pela Profa. Dra. Inês Moresco-Danni (UFPR), a melhor amiga. Ao longo da homenagem, a fala da professora Inês destacou as lembranças da vivência que ambas tiveram em São Paulo, quando desenvolviam seus estudos de doutoramento no Programa de Pósgraduação em Geografia Física da Universidade de São Paulo (USP), como também apresentou um pequeno vídeo com imagens, momentos e nomes de ex-orientandos.

No terceiro dia, a mesa redonda II intitulada: Climatologia e Gestão do Espaço Urbano teve a coordenação do Prof. Adeildo Cabral da Silva (IFET-CE), tendo como palestrantes a Profa. Margarete Cristiane de Costa Trindade Amorim (UNESP-PP) a Profa. Erika Collischonn (UFPel). A noite, realizou-se a mesa III denominada Climatologia e Gestão do Espaço agrário, cuja mediação ficou a cargo da Profa Zilda de Fátima Mariano (UFG-Jataí); do Prof. Vincent Dubreuil
(Université Rennes II) do Prof. Bernardo Barbosa de Silva (UFCG).

No quarto dia, na parte da manhã, ocorreu a mesa IV: Impactos, vulnerabilidades, riscos e adaptações à variabilidade e mudanças climáticas coordenada pelo Prof. Lucas Barbosa e Sousa (UFT), e que contou com a presença dos professores: João Lima Sant'Anna Neto - (UNESP/ PP); Magaly Mendonça (UFSC) e Francisco Mendonça (UFPR). Após o término da mesa IV, a conferência de encerramento foi conduzida por Alexandre Araújo Costa, Professor da Universidade Estadual do Ceará - UECE e da Fundação Cearense de Meteorologia e recursos hídricos- FUNCEME, que conduzio sua fala com a temática: Dimensões regionais e locais das mudanças climáticas globais. Cabe informar ainda, que as palestras proferidas pelos palestrantes convidados se encontram na Revista Mercartor, v. 9, n. 1, 2010, disponível no link http://www.mercator.ufc.br/.

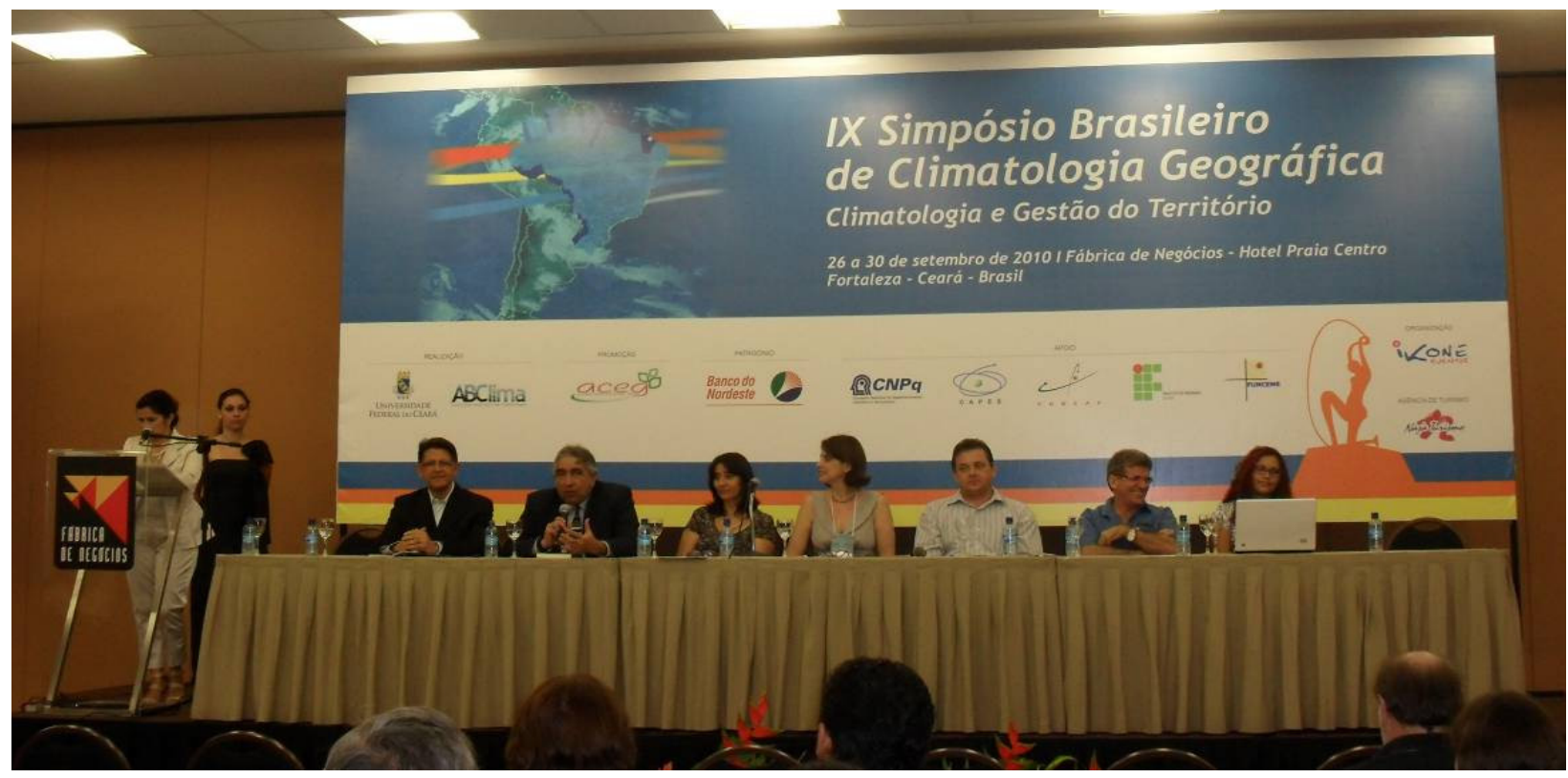

Após a conferência final foi instalada a assembléia da ABClima, presidida pelo Prof. Dr. Emerson Galvani (Presidente da diretoria 2008 a 2010) durante a qual foi apresentado um balanço das atividades da diretoria. Após o encerramento dessa parte mais burocrática foram apresentadas as cidades candidatas que pleitearam o direito de organizar o X SBCG em 2012, quando o evento completa 20 anos de existência. A primeira a apresentar sua candidatura foi Rio Claro 
(UNESP), em seguida Manaus, que em duas outras oportunidades (2000 e 2008) não obteve êxito na eleição para organizar o SBCG.

Após as apresentações, o processo de definição dos presentes aptos a votação foi conturbado e gerou um atraso do inicio da votação, causando um mal - estar desnecessário. Sanado o impasse depois de muita discussão, a votação de todos os presentes na sala, em que se realizava a assembleia, definiu por maioria que a cidade de Manaus fosse indicada para sediar o próximo SBCG, no ano de 2012, quando o SBCG, completará 20 anos de existência.

Por fim, foi apresentada única chapa para compor a nova diretoria da ABClima, que terá como presidente da gestão (2010-2012) o Prof. Washington Assunção (UFU), tendo como vicepresidente o Prof. Francisco Evandro (UFAM), que será o coordenador geral do próximo evento, e como Secretário Executivo o Prof. Charlei Aparecido da Silva (UFGD). 